В. А. Калмыкова

преподаватель

\title{
ФОРМИРОВАНИЕ МЕЖКУЛЬТУРНОЙ КОМПЕТЕНЦИИ У УЧАЩИХСЯ НА ОСНОВЕ АУТЕНТИЧНЫХ ТЕКСТОВ В ПРОЦЕССЕ ОБУЧЕНИЯ НЕМЕЦКОМУ ЯЗЫКУ
}

У статті розглянуто можливості використання автентичних текстів та їх роль для формування полікультурної комунікативної компетенції в процесі викладання шкільного курсу німещької мови

В современной методике обучения иностранным языкам владение и процесс овладения иноязычной коммуникативной деятельностью квалифицируются как межкультурная коммуникация. Проблема формирования межкультурной компетенции у учащихся общеобразовательных школ рассматривалась в недавних публикациях Л. П. Голованчука, Ю. В. Кузьменко, И. В. Корейбы. К числу особенностей межкультурной коммуникации в условиях средней школы относится использование аутентичных материалов, которые содержат культурные ссылки. В европейской методической литературе последнего времени проблеме аутентичности (в пер. с греч. «соответствующий подлинному», в пер. с англ. - «естественный») уделяется большое внимание. Несмотря на различные трактовки, обычно аутентичным называют текст, который специально не обработан и не был изначально предназначен для учебных целей $[3 ; 4 ; 5]$. Такой текст отражает естественное языковое употребление. Интегрирование аутентичных текстов в школьную практику приобретает все большее значение. Обучение немецкому языку должно быть построено так, чтобы учащийся сам естественно и органично пришел к необходимости продуцировать именно те аутентичные тексты, которые предусмотрены преподавателем. Школьник должен достаточно хорошо знать часть культурных образцов, о части культурных образцов иметь представление и адекватно реагировать на речевой и неречевой поведенческий коды своего иностранного собеседника.

$$
-130-
$$


Межкультурное обучение охватывает целый ряд отдельных аспектов, начиная от лингвистических (обучение безэквивалентной лексике и др.), прагматических (как правильно вести себя в конкретной ситуации), эстетических (что считается красивым или отталкивающим в иной культуре) и заканчивая этическими (что представляют собой моральные ценности) проблемами [4]. В ходе межкультурного обучения используются различные стратегии. Одна из первых - стратегия аутентичности учебного материала - учебников и учебных пособий, теле- и радиопрограмм, фильмов и прессы, то есть полное соответствие учебного материала всем реалиям страны изучаемого языка. Вторая стратегия предполагает погружение учащихся в языковую аутентичную среду. Для адекватной межкультурной коммуникации с носителями языка достаточно иметь необходимый социальный фон, в контексте которого функционирует изучаемый язык. Эту задачу достаточно полно способен решить аутентичный текст [2]. Любые материалы должны отражать страноведческую специфику, обладать культурологической ценностью. Поэтому следует учесть, прежде всего, критерий культурологической и страноведческой ценности. Школьникам, без сомнения, будет интересно узнать не только о том, что отличает культуру их страны от культуры немецкоязычных сверстников, но и о том, что их роднит. Так, например, немецкие школьники тоже любят посещать дискотеки, играть в баскетбол, кататься на роликах, играть в компьютерные игры. Исходя из этого, можно вводить соответствующие слова и выражения: Computer, Rollschuhe, Disco, Bewerbung, Tipps, fit, cool.

Одним из критериев отбора аутентичного материала является критерий типичности. Он призван обеспечить отбор страноведческого материала (в том числе и языкового), отражающего наиболее актуальные факты современной действительности страны изучаемого языка и создающего более точное представление об этой стране. С учетом данного критерия по каждой теме отбираются тексты, где отражены наиболее типичные реалии; безэквивалентная и фоновая лексика, предполагающая знакомство с какойлибо конкретной стороной жизни страны изучаемого языка: названия денежных единиц, названия некоторых праздников, символика страны и т. д.

Следующим критерием отбора страноведческих фоновых знаний должны быть их современность и общеизвестность в среде носителей языка. Например, каждый немецкий школьник знает, что отметка «5»- это плохая отметка. При счете немцы разгибают пальцы руки, начиная с большого.

Важным критерием является и адресат отбора. Учащиеся 9-11 классов проявляют заинтересованность ко многому из того, что связано с немецкоязычными странами: это праздники (какие и как их отмечают), компьютерные игры, герои фильмов, денежные единицы, школа, взаимоотношения в семье, идеалы и так далее.

Включение отобранного лексического материала и фоновых знаний в содержание обучения немецкому языку в старших классах предполагает овладение учащимися следующими знаниями и умениями:

$$
-131-
$$


1) знаниями фоновой лексики в рамках изучаемой тематики; некоторых достопримечательностей страны изучаемого языка; государственной символики;

2) умениями употреблять формулы речевого этикета в ситуациях: знакомство, приветствие, прощание, поздравление и другое; сравнить праздники, дни рождения сверстников в стране изучаемого языка и в своей стране; участвовать в различных видах деятельности, в которых нашли отражение и объяснение типичные исторические и культурные события страны в рамках изучаемых тем (викторина, неделя немецкого языка и др.); принимать участие в культурных мероприятиях, связанных с национальными праздниками и обычаями.

В условиях школы не всякий аутентичный текст может быть эффективным. В связи с этим представляется целесообразной адаптация аутентичных текстов. Рассмотрим совокупность структурных признаков учебного текста, отвечающего нормам, принятым носителями языка. Прежде всего, такой текст представляет собой аутентичный дискурс. Дискурс - это текст, взятый в событийном аспекте; это речь, рассматриваемая как целенаправленное социальное действие, как компонент, участвующий во взаимодействии людей. Дискурсивно аутентичный текст характеризуется естественностью лексического наполнения и грамматических форм, ситуативной адекватностью используемых языковых средств, иллюстрирует случаи аутентичного словоупотребления. Такому тексту присущи логическая целостность и тематическое единство [3].

Для аутентичного текста характерна структурная аутентичность. Это понятие связано с особенностями построения текста, его логикой, содержательной и формальной целостностью. В аутентичном тексте отдельные предложения тесно связаны и взаимно дополняют друг друга. Между ними устанавливаются логические отношения, возникают тема-рематические цепочки, обеспечивающие коммуникативную целостность текста.

Тема текста также определяет его связность. Ее установление является первым шагом к пониманию текста. Здесь важную роль играет заголовок. Он настраивает на восприятие определенной информации, создает условия для прогнозирования. В учебниках по иностранному языку распространены заголовки с номинативной функцией, называющие тему текста, например, «Mein Zimmer». Встречаются и более сложные модели: заголовкивопросы, привлекающие внимание учеников, например, «Sind Sie mit den Eltern zufrieden?», а также заголовки, являющиеся своего рода загадкой, например, «Die Kunst, falsch zu reisen». Понять смысл последнего заголовка можно, лишь ознакомившись с содержанием сообщения. Такие заголовки вызывают интерес у обучаемых, повышают мотивацию.

Следующим параметром является лексико-фразеологическая аутентичность. Отбор лексики и фразеологии играет важную роль в достижении аутентичности высказывания. Лексическое наполнение текстов, созданных

$$
-132-
$$


зарубежными авторами - носителями языка, более разнообразно. Эти тексты включают слова и выражения, типичные для разговорной речи, термины, множество прилагательных эмоционально-оценочного характера. Таким образом школьники знакомятся с аутентичной лексикой, разнообразной по тематике и принадлежащей к различным стилям речи. Идиоматичность и экспрессивность придают тексту фразеологические обороты. Они обладают национальной спецификой, определяемой особенностями языка, и именно поэтому их понимание и употребление вызывают трудности у иностранцев. Аутентичный текст является прекрасным материалом для ознакомления с фразеологией изучаемого языка и работы над ней. Знакомство с пословицами и фразеологическими оборотами формирует у обучаемых навыки аутентичного речевого поведения, а сопоставление немецкой и украинской фразеологии неизменно вызывает эмоциональный отклик и повышает интерес к предмету. Акцентируя внимание учащихся на общих и особенных чертах немецкой и украинской фразеологии, учитель формирует у них привычку к вдумчивому, аналитическому отношению как к иностранному, так и к родному языку. Устойчивые выражения, звукоподражания, восклицания, заполнители пауз, фразеологические единицы придают учебному тексту подлинный национальный колорит и аутентичность.

Следующим параметром аутентичного текста является его грамматическая аутентичность. Она связана с использованием в устной и письменной речи свойственных для данного языка структур. Грамматически аутентичное оформление фразы не менее важно, чем аутентичное лексическое наполнение.

Функциональная аутентичность также является важным параметром аутентичного текста. Это понятие подразумевает естественность отбора лингвистических средств для решения речевой задачи. Овладение умением выбора оптимального в конкретной ситуации средства выражения мысли одна из важнейших задач при изучении иностранного языка. Именно употребление неуместных в том или ином случае слов и выражений делает нашу речь на иностранном языке неаутентичной, хотя и не мешает ее пониманию. Чтобы помочь учащимся усвоить разговорные формулы, присущие данному языку, в современные учебники включаются тексты, иллюстрирующие стандартные ситуации общения и обучающие речевому поведению в различных жизненных обстоятельствах.

Аутентичному тексту присущи статистические особенности. Числовые показатели могут варьироваться в зависимости от жанра текста, его назначения, особенностей авторского стиля и так далее. Сопоставление результатов статистического анализа различных текстов предоставляет интересный материал для наблюдения и выводов [3].

Обучение естественному живому языку возможно лишь при условии использования материалов, взятых из жизни носителей языка или составленных с учетом особенностей их культуры и менталитета, в соответствии

$$
-133-
$$


с принятыми речевыми нормами. Методически аутентичный текст представляет собой естественное речевое произведение, созданное в методических целях [3].

В настоящее время учитель имеет широкие возможности использовать в своей работе аутентичные материалы из немецких пособий, молодежных журналов и газет, также очень актуально использование видео- и аудиоматериалов. Выбираемый текст должен соответствовать определенным требованиям. Он должен быть информативным и интересным, чтобы ученики могли удовлетворить свои познавательные потребности, обогатить свое мироощущение, свои представления о культуре и истории страны изучаемого языка и получить удовольствие от чтения и обсуждения текста. Удачно подобранный текст максимально стимулирует языковую активность учащихся и их коммуникативную готовность.

Работа над аутентичным текстом включает три этапа: предтекстовый, текстовый и послетекстовый. Предтекстовый этап должен обеспечивать «плавное вхождение» в текст. Необходимо снять лексические и грамматические трудности, выявить основную мысль и второстепенные факты, причинно-следственные связи и так далее, усвоить некоторые необходимые языковые единицы, чтобы учащийся мог использовать текст для порождения достаточно самостоятельного собственного высказывания. Предтекстовый этап состоит из лингвострановедческого комментария, работы с незнакомыми словами текста и предтекстовых упражнений (работа по картинкам (описание), работа с заглавием текста, работа со стихотворением к теме текста, составление ассоциограммы к теме текста и т. д.).

Текстовый этап - это самочтение, важным фактором которого является коммуникативная задача, предпосланная тексту для чтения, содержащая указание на глубину проникновения в текст и ориентировку на возможное речевое произведение. В зависимости от целевой установки выбирают просмотровое, ознакомительное, изучающее и поисковое чтение. Зрелое умение читать предполагает как владение всеми видами чтения, так и легкость перехода от одного его вида к другому в зависимости от изменения цели получения информации из данного текста. Текстовый этап включает в себя смысловое чтение, а также упражнения, направленные на извлечение основной и второстепенной информации из текста посредством нахождения информации, отражающей его смысл, лексико-тематическую основу объединения смысловых отрезков в единое целое.

Нужно заметить, что часто текст читается сначала с пониманием основного содержания, а затем послетекстовые упражнения ориентируют на повторное (иногда неоднократное) возвращение к тексту с целью понять детали, проникнуть, если нужно, в подтекст. Послетекстовый этап должен обеспечить проверку понимания текста и дальнейшую работу по углублению понимания (информационную переработку) текста. Упражнения по работе над текстом при взаимосвязанном обучении чтению и говорению

$$
-134-
$$


должны содержать задания, которые нацелены на порождение собственного высказывания.

Послетекстовый этап может содержать ответы на вопросы, устные описания, формулировку вопросов к тексту самими учащимися, эквиваленты предложений к тексту, различные задания творческого характера и так далее. На этом этапе приемы оперирования направлены на выявление основных элементов содержания. В послетекстовых заданиях необходимо осуществлять проверку понимания содержания текста (основного или деталей в зависимости от установки на глубину проникновения в содержание). Если перед чтением текста учащимся ставится задача - высказать свои предположения по развитию содержания текста, то в послетекстовых заданиях должен присутствовать вопрос, подтвердились они или нет. Часто осуществляется работа над средствами языка (лексикой или грамматикой), что предполагает повторное возвращение к тексту. Еще раз обратиться к нему необходимо, если дается задание по поиску ключевых слов, ответов на вопросы к тексту, поиску определенной информации и занесению ее в таблицу, составление плана и так далее. На основе текста учитель организует выполнение упражнений с целью выявления уровня понимания его содержания, усвоения лексико-грамматического материала и развития коммуникативных умений в говорении на основе содержания текста. Говорение на основе текста - это предпосылка для качественного осуществления ситуативного (неподготовленного) говорения.

Для того чтобы аутентичный текст стал реальной продуктивной основой обучения всем видам речевой деятельности, важно научить обучаемых различным операциям с материалами текста, разнообразным манипуляциям с разнохарактерными единицами - предложением, сверхфразовым единством, субтекстом и текстом с учетом жанровых и стилистических особенностей определенного класса и исходного (образцового) текста, навыкам и умениям дифференциации, реконструирования, трансформации и конструирования языковых единиц в решении определенной учебной задачи (например, пересказа текста, его использования в коммуникативнообращенном устном монологическом высказывании, диалоге, письменном сообщении и т. д.).

Сегодняшний день требует от обучения максимальной эффективности и практической реализации знаний учащихся. Учитель немецкого языка средней школы должен не просто владеть теоретическими знаниями, абстрактными понятиями, обобщениями, предсказательными возможностями, но и уметь проанализировать отношение: получить знания и понять культуру народа, изучаемого языка, развивать умения по отбору содержания для учебного материала. Использование аутентичных текстов на уроках иностранного языка - один из оптимальных вариантов повышения уровня поликультурного образования. Программный материал и построение учебных комплексов по иностранному языку дают учителю возмож-

$$
-135-
$$


ность последовательно использовать аутентичные тексты в учебном процессе. А эффективность работы с аутентичными текстами состоит, прежде всего, в том, что они создают языковую среду на уроке. Чтобы ученики с интересом изучали другой язык, чтобы им не было скучно на уроке знакомиться с другой культурой, чтобы они видели реальную возможность применения полученных знаний, учитель должен умело подбирать и правильно сочетать различные формы и приемы работы над аутентичными материалами.

\section{Список использованной литературы}

1. Барышников И. В. Параметры обучения межкультурной коммуникации // Иностранные языки в школе. - 2002. - №2. - С. 28.

2. Мильруд Р. П. Методика обучения видам речевой деятельности на иностранном языке. Методические рекомендации. - Тамбов, 1995.

3. Носонович Е. В. Методическая аутентичность в обучении иностранным языкам // Иностранные языки в школе. - 2000. - №1. - С. 11-16.

4. Носонович Е. В. Параметры аутентичного учебного текста // Иностранные языки в школе. - 1999. - №1. - С. 18.

5. Синица Ю. А. Межкультурная коммуникативная компетенция: требования к уровню владения и некоторые пути ее формирования // Иностранные языки в школе. - 2002. - №6. - С. 8.

\section{Summary}

The article deals with the possibilities of usage original texts and their role in pupils 'developing intercultural communicative competence. 